\title{
To Plate or Not to Plate after a Single- or Two- Level Anterior Cervical Discectomy: Fusion with Cage-Plate Construct or Stand-Alone Cage
}

\author{
V.K. Viswanathan ${ }^{1}$, S.R. Manoharan ${ }^{2}$ \\ ${ }^{1}$ Ohio State Medical Center, Columbus, OH, USA \\ ${ }^{2}$ Birmingham Medical Center, University of Alabama, Birmingham, AL, USA
}

Anterior cervical discectomy and fusion (ACDF) is one of the most common spine surgeries performed as the treatment for diverse cervical spine diseases including degenerative spondylosis, disc prolapse, trauma, infections and instability [1]. The purpose of this surgery is to decompress the spinal cord and nerve roots, as well as to achieve inter-vertebral stabilization [2].

Cervical disc arthroplasty is another popular way of reconstructing cervical spine after discectomy, nevertheless fusion with inter-body cage still remains the goldstandard [3]. Multifarious ways to fuse have been practised: bone graft or bone graft substitute augmented by an anterior plate, stand-alone strut graft, inter-body cage with anterior plate, stand-alone cage and zero-profile cage [2]. Of these, the most common fusion techniques include anterior cervical fusion with stand-alone cage or cageplate construct.

The pros and cons of each of these techniques have been broadly described in the literature. Whether an additional plate fixation renders any specific advantages over standalone cage in single- or two-level fusion is still unclear. Song et al. [4] observed that significantly better lordosis, greater disc height, higher fusion rates, lower subsidence and fewer complications could be achieved with cageplate constructs in 1- or 2-level ACDF. Using the plate system, increased stability, better graft extrusion prevention and increased fusion rates may be observed, nonetheless at the additional risks of enhanced costs and higher chances of hardware failure. Anterior plating is wellknown to have inherent deficiencies including screw pullout, loosening of plate, hardware breakage and irritation of esophagus and other vital structures. The additional plate insertion also adds to the operative time [5]. Ji et al. [6] compared 22 patients with 2-level discectomies who underwent anterior cervical fusion with stand-alone cages with 20 patients with cage-plate construct. They observed similar fusion rates and clinical outcome (using Robinson criteria) in both groups at 2-year follow-up. There were no differences between the two groups in terms of radiological parameters including anterior osteophyte formation or anterior longitudinal ligament calcification, although adjacent segment degeneration (inter-vertebral disc space narrowing) was significantly lower in the stand-alone cage group. Adjacent segment degeneration or disease has been associated with inappropriately-sized anterior cervical plates and has especially been related to greater proximity

Received Jan 11, 2017; Accepted Jan 11, 2017

Corresponding author: S.R. Manoharan

University of Alabama, Birmingham Medical Center, FOT 960, 20th St S Birmingham, AL, USA 35294.

Tel: +205-934-8718, E-mail: srajaram@uabmc.edu 
of the plate to disc space (less than $5 \mathrm{~mm}$ from intervertebral disc) [7].

The rationale behind stand-alone cage in ACDF was discussed by Bagby [8] as the distraction-compression principle. He described that tensioning of the annulus and ligaments occurred secondary to physiological stresses of neck movements when cages of appropriate sizes were inserted in the inter-vertebral disc space. This resulted in an inherent stability of a stand-alone construct, without an additional need for plate fixation. However, the two major concerns over stand-alone cage constructs have been risks of subsidence and focal sagittal malalignment.

Subsidence is an important radiological phenomenon, which has a bearing on the long-term foraminal area reduction after ACDF. In a study assessing the radiological subsidence following standalone PEEK cages in one- or two-level ACDF, subsidence $>3 \mathrm{~mm}$ was $8.1 \%$ [9]. In the study by $\mathrm{Oh}$ et al. [10], among 54 patients who underwent anterior cervical discectomy and reconstruction at two levels, cage-plate constructs resulted in shorter fusion duration and lower subsidence rates; although all other clinical and radiological parameters including global and segmental alignment were similar in both groups. Lee et al. [11] observed better prevention of segmental kyphosis and subsidence with cage-plate constructs. Bartels et al. [12] reported subsidence in $29.2 \%$ and non-union in $4.3 \%$ following stand-alone cages. Similar results of increased subsidence and non-union were reported by Yang et al. [9]. However, the clinical outcome with stand-alone cage was not adverse, despite these negative radiological measures in all these studies. All other radiological outcome measures were also satisfactory with the stand-alone cage construct [9-12].

The stand-alone cages have been demonstrated to be sufficiently effective in inducing fusion in singleor twolevel fixations. Pitzen et al. [13] observed similar fusion rates between anterior cervical fusion with standalone cages (90.3\%) and cage-plate constructs (91.3\%). Most of the studies in literature demonstrate overall satisfactory clinical outcome following both these techniques (standalone cage and cage-plate construct) [9-13]. Lee et al. [11] demonstrated that patients with cage-plate constructs showed greater improvement in radicular arm pain than those with stand-alone cages, albeit similar clinical outcomes (Odom criteria and Visual analog scale) otherwise.

Subsidence of the cage is related to multifarious factors and does not just depend on presence or absence of a plate. Bartels et al. [12] discussed that cage subsidence was significantly higher at C6-7 level fusions. Barsa and Suchome [14] reported that greater distance between anterior rim of vertebral body and cage; and smaller contact surface area between cage and end plate were significant risk factors for the development of cage subsidence. It has also been demonstrated that low bone mineral density and enforcing excessive distraction across the disc space during cage insertion are other risk factors for cage subsidence. Using a cage with large AP diameter, performing inter-body distraction prior to anterior longitudinal ligament resection, ensuring proper preparation of end plates to reduce bony damage and selecting a cage with proper height are strongly recommended to prevent cage subsidence [12-14].

The financial logistics regarding cervical ACDF also deserve to be kept in mind. The average costs for ACDF range from $\$ 11,000$ to $\$ 25,000$ [15]. The addition of an anterior plate and screws contributes to the enhanced expenditure and surgical time. Whether such plate augmentation needs to considered as a routine procedure in all ACDF surgeries, has to be seriously introspected by spine surgeons and the decision to add plate fixation rather needs to be made on a case to case basis. Additional plate augmentation definitely needs to be considered in multilevel fusions, traumatic situations, osteoporotic bones, breached end plates, sagittal malalignments or in other situations where greater chance of cage subsidence exists [16]. Nevertheless, it may be recommended from the literature evidence that a stand-alone cage fusion performed in a carefully selected patient using the right technique should be sufficient in a majority of patients.

\section{Conflict of Interest}

No potential conflict of interest relevant to this article was reported.

\section{References}

1. Cloward RB. The anterior approach for removal of ruptured cervical disks. J Neurosurg 1958;15:602-17.

2. Botelho RV, Dos Santos Buscariolli Y, de Barros Vasconcelos Fernandes Serra MV, Bellini MN, Bernardo WM. The choice of the best surgery after single level anterior cervical spine discectomy: a systematic review. Open Orthop J 2012;6:121-8. 
3. Maharaj MM, Phan K, Mobbs RJ. Anterior cervical discectomy and fusion (ACDF) autograft versus graft substitutes: what do patients prefer?-A clinical study. J Spine Surg 2016;2:105-10.

4. Song KJ, Taghavi CE, Lee KB, Song JH, Eun JP. The efficacy of plate construct augmentation versus cage alone in anterior cervical fusion. Spine (Phila $\mathrm{Pa}$ 1976) 2009;34:2886-92.

5. Singh P, Kumar A, Shekhawat V. Comparative analysis of interbody cages versus tricortical graft with anterior plate fixation for anterior cervical discectomy and fusion in degenerative cervical disc disease. J Clin Diagn Res 2016;10:RC05-8.

6. Ji GY, Oh CH, Shin DA, et al. Stand-alone cervical cages versus anterior cervical plates in 2-level cervical anterior interbody fusion patients: analysis of adjacent segment degeneration. J Spinal Disord Tech 2015;28:E433-8.

7. Uddanapalli SS. New classification for clinically symptomatic adjacent segment pathology in cervical disc disease. Asian Spine J 2015;9:942-51.

8. Bagby GW. Arthrodesis by the distraction-compression method using a stainless steel implant. Orthopedics 1988;11:931-4.

9. Yang JJ, Yu CH, Chang BS, Yeom JS, Lee JH, Lee CK. Subsidence and nonunion after anterior cervical interbody fusion using a stand-alone polyetheretherketone (PEEK) cage. Clin Orthop Surg 2011;3:16-23.
10. Oh JK, Kim TY, Lee HS, et al. Stand-alone cervical cages versus anterior cervical plate in 2-level cervical anterior interbody fusion patients: clinical outcomes and radiologic changes. J Spinal Disord Tech 2013;26: 415-20.

11. Lee $\mathrm{CH}$, Hyun SJ, Kim MJ, et al. Comparative analysis of 3 different construct systems for single-level anterior cervical discectomy and fusion: stand-alone cage, iliac graft plus plate augmentation, and cage plus plating. Clin Spine Surg 2013;26:112-8.

12. Bartels RH, Donk R, van Azn RD. Height of cervical foramina after anterior discectomy and implantation of a carbon fiber cage. J Neurosurg 2001;95:40-2.

13. Pitzen T, Kiefer R, Munchen D, Barbier D, Reith W, Steudel WI. Filling a cervical spine cage with local autograft: change of bone density and assessment of bony fusion. Zentralbl Neurochir 2006;67:8-13.

14. Barsa P, Suchomel P. Factors affecting sagittal malalignment due to cage subsidence in standalone cage assisted anterior cervical fusion. Eur Spine J 2007;16: 1395-400.

15. Goz V, Rane A, Abtahi AM, Lawrence BD, Brodke DS, Spiker WR. Geographic variations in the cost of spine surgery. Spine (Phila Pa 1976) 2015;40:1380-9.

16. Ha SK, Park JY, Kim SH, Lim DJ, Kim SD, Lee SK. Radiologic assessment of subsidence in stand-alone cervical polyetheretherketone (PEEK) cage. J Korean Neurosurg Soc 2008;44:370-4. 